\title{
The Institut Mittag-Leffler and its Archives: A Mathematician and his Legacy
}

Eva Kaufholz-Soldat (Johannes Gutenberg-Universität, Mainz, Germany)

It is quite impossible to write about the history of the Institut Mittag-Leffler (IML) without, at the same time, discussing the mathematician who conceived it and after whom it is named. ${ }^{1}$

In writing his obituary, G.H. Hardy noted that "[t]here have been greater mathematicians during the last fifty years, but no one who has done in his way more for mathematics" [10, p. 160]. And, indeed, even though he produced quite deep results during his active years, Gösta Mittag-Leffler is mostly remembered for his vital role in the mathematical community at the turn of the century and as the founder of Acta Mathematica, which appeared in 1882 for the first time. André Weil aptly called Mittag-Leffler's new journal his deed of true genius [24, p. 12].

Its success as one of the first truly international journals was partly due to Sweden's neutrality, making it possible for French and German mathematicians to publish in the same journal roughly a decade after the FrancoPrussian War [2,5]. But, even more importantly, Acta was a testimony to Mittag-Leffler's outstanding organisational talent, including his ability to find a number of prominent sponsors, the Swedish King Oscar II among them. And when he married Signe Lindfors the very same year, their romantic honeymoon trip through Europe was surely dampened by the fact that he was constantly meeting with French and German mathematicians in order to secure publications for Acta [2, pp. 6, 8].

Already a decade before, Mittag-Leffler had made important contacts in Berlin and Paris, the two foremost mathematical centres at the time. It was in May 1872, right after he finished his dissertation, that he was awarded the Byzantine Grant, which allowed him to travel to Central Europe, a trip that proved decisive for the rest of his mathematical career [22, pp. 143ff].

In Paris, he got to meet Charles Hermite, from which a friendly relationship developed that lasted until the latter's death in 1901. An extensive correspondence bears witness to that friendship, which was especially important for Mittag-Leffler in helping him make connections with the French mathematical community and for securing publications for Acta. While the letters from Hermite to Mittag-Leffler were edited and published by Pierre Dugac [6-8], the other side of the exchange still exists in the IML in the form of drafts, waiting for anyone willing to battle with Mittag-Leffler's difficult handwriting.

My grateful thanks to both Mikael Rågstedt and David E. Rowe for their valuable help and suggestions for this article.
It was in 1881 that Mittag-Leffler first wrote to Henri Poincaré, soon after Hermite had called his attention to this talented young mathematician, who had just finished his doctoral thesis under his direction. Their subsequent letters along with other archival materials relating to Poincaré at the IML are without doubt among the better known holdings there. In 1999, Philippe Nabonnand (Poincaré Archives, Nancy) edited and published this correspondence. Unlike many others, Mittag-Leffler kept his letters to Poincaré on a strictly professional level, whereas for Poincaré it is the most regular and extensive scientific correspondence that has been preserved [18]. As a result, their symbiotic relationship is very well documented. From the very beginning, Mittag-Leffler recognised Poincaré's potential and he would continue to promote him throughout his career.

He also hoped that Poincaré would play a role for Acta similar to the one Niels Henrik Abel had so importantly played for Crelle's Journal für die reine und angewandte Mathematik. In the late 1820s, Abel's publications had helped launch this fledgling journal, which quickly became one of the most renowned mathematical publications of its time [14, p. 199]. Mittag-Leffler was not to be disappointed. Indeed, many of Poincaré's most important papers would appear under his editorship, such as his publications on Fuchsian functions and, of course, his now famous contribution on the n-body-problem, which won the prize established in honour of King Oscar II of Sweden. At first, however, it was overlooked that Poincaré's original paper, published in Acta in 1889, contained such a serious error that the issue had to be reprinted. Poincaré reworked that article and, in the new version, he presented what could be considered a first description of chaotic behaviour, even though this concept would only be formulated much later, in 1960, when Edward Lorenz introduced modern chaos theory [1]. Scans of some of the documents concerning this dramatic episode in the history of modern mathematics can be found on the IML's homepage, together with a short overview of the events. ${ }^{2}$ Unfortunately, no other documents are available online as yet, nor is there an index of all the material that can be found on-site (this would be very helpful).

According to Mittag Leffler, it was partly due to Hermite's influence that he met Weierstraß for the first time. Unlikely as it may seem, the French mathematician supposedly advised him to go to Berlin to attend his lectures, calling him the "master of us all". Not long after his arrival

\footnotetext{
2 http://www.mittag-leffler.se/library/prize-competition.
} 
bear his name after his death fitted perfectly with his mindset.

Probably inspired by the wish to realise this dream but also to ensure that his own ideas would not be misconstrued, he set these down a decade later in his last will and testament. Therein, he designated that on his 70th birthday, he would bequeath his villa and fortune to the Royal Swedish Academy of Sciences, under the condition that they use both to found a mathematical institute. ${ }^{4}$

That date fell in the middle of the Great War so the official opening was postponed until 1919. Nevertheless, it remained a pure formality $[9$, p. 364] and it was only long after Mittag-Leffler's death in 1927 that his dream would become a reality. After the IML had lain more or less dormant for several decades, discussions about closing it for good began to surface. But, luckily enough, Lennart Carleson had different ideas and he was in a position to act on them. In 1966, he had proven a conjecture by Nikolai Luzin about the convergence of certain types of Fourier series, a result so impressive that he received numerous job offers from universities in the United States. To discourage him from relocating, the Swedish government awarded him a special professorship, which allowed him to work wherever he wanted. And so he chose to go to the $I M L$, taking up residence there a mere year later. From there, he began efforts to secure the necessary financial means and he was able to play the role of Prince Charming, whose kiss reawakened the Sleeping Beauty of the old villa, which could now begin to bloom as an international research institute.

In doing so, Mittag-Leffler mysteriously came to assist him from beyond the grave [11, p. 1053f]. As it happened, the cellars of his villa were filled with countless complete sets of Acta Mathematica, some of them probably intended for a special purpose. For Mittag-Leffler had not only bequeathed his fortune to establish the $I M L$, he had also designated how this was to be spent. Part of the funding was to be earmarked for stipends to support young mathematicians from the Nordic countries and, if their work proved to be of exceptional quality, to reward them with gold medals and a complete set of the journal [22, p. 584]. Now, however, at a time when universities were expanding worldwide, the Institut had the opportunity, instead, to sell several hundred of these, thereby contributing to its solid financial basis as an added bonus for Carleson's endeavours [11, p. 1053].

Ever since that time, the villa has served as an international research institute, hosting numerous longer mathematical programmes, now supplemented with conferences during the Summer. Mathematical topics have regularly been set by the directors for up to one year, during which leading experts and young research schol-

\footnotetext{
4 While Mittag-Leffler suffered serious financial setbacks during the latter stages of his life, in part because his financial advisors took advantage of him, there are no sources confirming that this was motivated by an imminent loss of his possessions due to any depreciation of investments in German bonds during World War I, as claimed earlier by Ivor Grattan-Guinness [9, p. 364].
}

ars working in the chosen field are invited to attend. But, under Carleson's directorship, the IML has also become an important repository of historical documents. While it would take until the 1990s before Reinhard Bölling systematically ordered and catalogued the archival materials on-site [20, p. 9], 20 years earlier Ivor GrattanGuinness had taken a first look at the treasures hidden in various boxes and cabinets. He was delighted to find that he could now determine - at least partly - "the whereabouts, or fate, of Weierstraß's Nachlass" [9, p. 365]. Later, Gert Schubring discovered a small number of Weierstraß's letters in Berlin [21].

That most of Weierstraß's personal papers are now located in a country that played no role in his career is, of course, due to Mittag-Leffler, who procured them after the Nachlass had passed through many hands. After Karl Weierstraß died in 1897 , his estate was initially handled by his former student and confident Johannes Knoblauch, at the request of Weierstraß's sister Elise, but was later given to their brother Peter, who passed away in 1904. None of the Weierstraß siblings had (legitimate) children, ${ }^{5}$ so there was no official heir. Thereafter, Mittag-Leffler contacted H. Schulz, who was apparently the husband of Peter's housekeeper during the last months of his life and acted as a custodian for his estate. MittagLeffler persuaded him to sell him "a small mountain" of correspondence, some original writings, diplomas, official documents and paintings of the Berlin mathematician in his name. And, thus, a significant part of Weierstraß's Nachlass was moved to his home in Djursholm. In later years, it even grew larger as other mathematicians - Eugen Netto, Georg Cantor, Paul du Bois-Reymond and Leo Königsberger - also agreed to hand over their respective correspondence with Weierstraß to MittagLeffler [20].

That Mittag-Leffler tried to save as much as possible of Weierstraß's papers can only partly be explained as a wish to ensure these documents would not get lost over time. As has already been mentioned, he modelled his own lecture courses on those given by the Berlin mathematician. He did so, however, not only to spread the principles of his idol but also in order "to appropriate a part of the legacy of the great Weierstrass for himself" [14, p. 118]. So his motivation, once again, had much to do with fashioning his own place in the history of mathematics. Already in the early 1880s, he had been strengthening his bonds with Weierstraß, particularly when, through much personal effort, he managed in 1883 to appoint the latter's "favourite pupil", Sofia Kovalevskaya, at the högskola in Stockholm.

Ever since, Kovalevskaya has attracted a great deal of attention: not only was she one of the first women to hold an official teaching position at a university, she was also a writer with connections to current radical political movements. Whereas her lecture notes and other math-

\footnotetext{
5 While none of the Weierstraß siblings officially had any children, there is a certain possibility that Karl fathered a son out of wedlock with the widow of his best friend Carl Borchhardt [3].
} 
ematical papers, as well as various manuscripts from her literary ventures, have remained largely untouched, much of her vast Nachlass at the IML has been used in biographical studies, most notably by Ann Hibner Koblitz and Pelageya Kochina [12, 13]. Another important publication stemming from her personal papers were the letters Weierstraß wrote to her, which were published by Reinhard Bölling in 1993 [4].

Still, Bölling was not the first to publish from this correspondence, as Mittag-Leffler himself had already cited letters from it in recounting the life of Weierstrass at the ICM held in Paris in 1900. It was only toward the end of his life, however, that Mittag-Leffler actually published several of the letters that would later find their way into Bölling's collection.

One reason for the delay was a promise he had made to Weierstraß. Deeply struck by the death of his very dear friend, the Berlin mathematician had burned all her letters to him but he allowed Mittag-Leffler to keep the ones he wrote to her under the condition that the Swede would not publish these before he died. Mittag-Leffler kept true to his word: not until 1923, more than 25 years after Weierstraß's death in 1897, did he publish excerpts from them. These appeared in an article in volume 39 of Acta that was based on Mittag-Leffler's lecture from 1900 [17].

That volume, like the preceding one, had been dedicated to the lives and scientific achievements of Karl Weierstraß, Henri Poincaré and Sofia Kovalevskaya, all of whom were, by then, long since deceased. As Mikael Rågstedt, the current librarian of the IML, has noted: "Mittag-Leffler throughout his life showed a special fascination with an exclusive group of mathematicians, [often behaving like] a knight who stood up for them and tried to restore them to their rightful scientific position." Certainly, Mittag-Leffler proved his loyalty to these three famous figures all his life but, as Rågstedt also noted, "chivalry is not the only qualification of a knight, and Mittag-Leffler also knew how to make use of his idols as armour and lances for his own ambitions" [20, p. 2]. In this spirit, his efforts to promote the careers of Poincaré and Kovalevskaya were not just a little self-serving. More striking still were his efforts to make himself the legitimate heir to Weierstraß's legacy by way of the biographical genre, an aim he pursued for decades with increasing zeal [14, p. 118]. This culminated in a long essay on his idol's life contained in [16], for which he could rely on those personal papers out of the Nachlass he had acquired almost 20 years earlier.

While Mittag-Leffler never finished the extensive biography of the Berlin mathematician he had hoped to write, it would certainly be wrong to claim that Weierstraß's Nachlass has been completely ignored since his time. Quite a few items from it have been cited in various publications since its rediscovery by Grattan-Guinness. Nevertheless, it still awaits a proper assessment as a whole. This would certainly shed more light on the life and work of one of the most important mathematicians of the 19th century, including the school he founded in Berlin, which is still lacking a comprehensive study.
Much the same could be said about another major resource found at the $I M L$, one which had already impressed André Weil when, as a fellow of the Rockefeller Foundation, he visited Mittag-Leffler in 1927, just months before the latter's death. What he discovered was Mittag-Leffler's correspondence with "the great ones of the past half-century; [...] all there to keep me company while everyone was asleep, opening up for me the secret recesses of their minds" [24, p. 11]. Here, one can find letters from the likes of Georg Cantor, Marie Curie, Gottlob Frege, G.H. Hardy, David Hilbert, Camille Jordan, Felix Klein, Sophus Lie and Paul Painlevé. As would be expected, much of this deals with matters concerning Acta, as Mittag-Leffler was always on the lookout for possible publications, very often with a remarkable instinct for groundbreaking advances.

As Mittag-Leffler had a tendency to keep records of everything, drafts of his own letters are also available in most cases, making it possible to reconstruct a fairly complete picture of his correspondence in many instances. While quite a few of these documents have been cited in various publications, most recently in Arild Stubhaug's biography of Mittag-Leffler [22], a full study of this correspondence would certainly be a most rewarding undertaking. For, as Weil rightly noted, Mittag-Leffler had a talent for turning colleagues into friends and the "rare quality of sympathy in the bonds of friendship which Mittag-Leffler had succeeded in establishing with men so diversely gifted, inducing them to confide their innermost thoughts to him with such abandon" is certainly striking [24, p. 11]. Thus, the letters bear witness to important advances in the discipline in a technical sense but also provide insights into what was going on behind the scenes, allowing for a rich and multifaceted picture of a larger part of the mathematical community at the time.

For security reasons, the originals of these letters have recently been moved to the Royal Swedish Academy of Sciences in Stockholm. Earlier, Mittag-Leffler's private materials (about 80 shelf metres), most notably including his diaries, were transferred to the National Library. Still, the IML has kept high quality copies of the scientific letters, which are easily accessible to anyone who feels inspired to follow in Weil's footsteps. As the $I M L$ also provides accommodation for researchers, the grand mansion in serene Djursholm offers ideal conditions either to study these or to tackle other historical papers, such as those in Weierstraß's Nachlass. And this can be done in virtually the same atmosphere that Mittag-Leffler enjoyed, breathing the spirit of the 19th and early 20th centuries in his spacious but charming rooms, furnished mostly with the original chairs, lamps and shelves of the day. But one can do that while taking advantage of the perks of the digital age, provided in most discrete ways so as not to disturb the enchanting atmosphere of a place that seems to have fallen out of time.

\section{References}

[1] June Barrow-Green, Poincaré and the Three Body Problem. American Mathematical Society, New York, 1997.

[2] June Barrow-Green, Gösta Mittag-Leffler and the Foundation and 
Administration of Acta Mathematica. In: Karen Hunger Parshall and Adrian C. Rice (Eds.), Mathematics Unbound: The Evolution of an International Mathematical Research Community, 1800-1945, pages 139-164, Providence, 2002. American Mathematical Society, London Mathematical Society.

[3] Kurt R. Biermann and Gert Schubring, Einige Nachträge zur Biographie von Karl Weierstraß. In: Joseph W. Dauben, Menso Folkerts, Eberhard Knobloch, and Hans Wussing (Eds.), History of Mathematics: States of the Art. Flores quadrivili - Studies in Honor of Christoph J. Scriba, pp. 65-89. Academic Press, San Diego u.a., 1996.

[4] Reinhard Bölling (Ed.), Briefwechsel Karl Weierstraß-Sofja Kowalewskaja. Akademie Verlag, Berlin , 1993.

[5] Yngve Domar, On the Foundation of Acta Mathematica. Acta Mathematica, 148(1): 3-8, 1982.

[6] Pierre Dugac, Lettres de Charles Hermite à Gösta Mittag-Leffler (1874-1883). Cahiers du séminaire d'histoire des mathématiques, 5: 49-285, 1984.

[7] Pierre Dugac, Lettres de Charles Hermite à Gösta Mittag-Leffler (1884-1891). Cahiers du séminaire d'histoire des mathématiques, 6 : 79-217, 1986.

[8] Pierre Dugac, Lettres de Charles Hermite à Gösta Mittag-Leffler (1892-1900). Cahiers du séminaire d'histoire des mathématiques, 10: $1-82,1989$.

[9] Ivor Grattan-Guiness, Materials for the History of Mathematics in the Institut Mittag-Leffler. Isis, 62(3):363-374, 1971.

[10] G.H. Hardy, Gösta Mittag-Leffler. Journal of the London Mathematical Society, 3: 156-160, 1928.

[11] Allyn Jackson, The Dream of a Swedish Mathematician: The Mittag-Leffler Institute. Notices of the AMS, 46(9): 1050-1058, 1999.

[12] Ann Hibner Koblitz, A convergence of lives: Sofia Kovalevskaia; scientist, writer, revolutionary. Birkhäuser, Boston, 1983.

[13]Pelageya Kochina, Love and Mathematics: Sofya Kovalevskaya. Mir Publishers, Moskau, 1985.

[14]Henrik Kragh Sørensen, Reading Mittag-Leffler's biography of Abel as an act of mathematical self-fashioning. In Benjamin War- daugh (Ed.), The History of the History of Mathematics, pp. 115144. Peter Lang, Oxford, 2012.

[15] Massimo Mazzotti, For science and for the Pope-king: writing the history of the exact sciences in nineteenth-century Rome. British Journal for the History of Science, 33: 257-282, 2000.

[16] Gösta Mittag-Leffler, Die ersten 40 Jahre des Lebens von Weierstraß. Acta Mathematica, 39: 1-57, 1923.

[17] Gösta Mittag-Leffler, Weierstrass et Sonja Kowalewsky. Acta Mathematica, 39:133-198, 1923.

[18] Philippe Nabonnand (Ed.), La correspondance entre Henri Poincaré et Gösta Mittag-Leffler. Birkhäuser, Berlin, 1999.

[19]David Rowe, Episodes in the Berlin-Göttingen Rivalry, 1870-1930. The Mathematical Intelligencer, 22(1): 60-69, 2000.

[20] Mikael Rågstedt, Prelude: Gösta Mittag-Leffler and his quest for the Weierstraß legacy. In Wolfgang König and Jürgen Sprekels (Eds.), Karl Weierstraß (1815-1897), pp. 1-9. Springer Spektrum, Wiesbaden, 2016.

[21] Gert Schubring, An Unknown Part of Weierstraß's Nachlaß. Historia Mathematica, 25(4): 423-430, 1998.

[22] Arild Stubhaug, Gösta Mittag-Leffler. Springer, Heidelberg u.a., 2010.

[23]Laura E. Turner, The Mittag-Leffler Theorem: The origin, evolution, and reception of a mathematical result, 1876-1884. Historia Mathematica, 40(1): 36-83, 2013.

[24] André Weil, Mittag-Leffler as I remember him. Acta Mathematica, 148(1): 9-13, 1982.

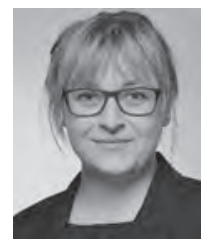

Eva Kaufholz-Soldat_[kaufholz@unimainz.de] is a PhD student in the history of mathematics at Johannes GutenbergUniversität, Mainz. She is currently writing her thesis on the reception of Sofia Kovalevskaya during the long 19th century. 